\title{
A Reliable and Cost-Effective Method for Determination of Endocrine-Disrupting Compounds in Coastal Waters, Suspended Particulate Matter, and Sediments by Ultrafast Liquid Chromatography Coupled to Photodiode Array and Fluorescence Detectors
}

\author{
Gabriel C. de Souza, ${ }^{\oplus *, a, b}$ Cristiane S. Fahning, ${ }^{\ddagger, c}$ Vanessa Hatje ${ }^{\circledR a, c}$ and Gisele O. da Rocha ${ }^{\oplus *, a, c, d}$ \\ ${ }^{a}$ Centro Interdisciplinar em Energia e Ambiente (CIEnAm), Universidade Federal da Bahia, \\ Ondina, 40170-290 Salvador-BA, Brazil \\ ${ }^{b}$ Observatório UniFG do Semiárido Nordestino, Centro Universitário UniFG, \\ 46430-000 Guanambi-BA, Brazil
}

'Instituto de Química, Universidade Federal da Bahia, 40170-290 Salvador-BA, Brazil

${ }^{d}$ Instituto Nacional de Ciência e Tecnologia em Energia e Ambiente (INCT E\&A), Universidade Federal da Bahia, 40170-290 Salvador-BA, Brazil

\begin{abstract}
Analytical methods for determining 14 endocrine-disrupting compounds (EDCs) in coastal waters, suspended particles, and sediment samples were successfully performed by ultrafast liquid chromatography with photodiode array and fluorescence detections (UFLC-PDA-FLD). Solid-phase extraction (SPE) and ultrasound-assisted extraction (USE) were used for sample preparation. Two chromatographic methods have been developed. An isocratic separation method was used to separate bisphenol A (BPA) and steroids and another gradient elution method to separate phthalates and alkylphenols. The detection by fluorescence was used for alkylphenols, BPA, and steroids and photodiode array (PDA) for phthalates. Limits of detection (LOD) ranged from 0.41 (4-tert-octylphenol (4tOP)) to $63 \mathrm{ng} \mathrm{L}^{-1}$ (dibutylphthalate (DBP)), 0.41 (4tOP) to $63.2 \mathrm{ng} \mathrm{g}^{-1}$ dried weight ( $\mathrm{dw}$ ) coastal waters, and solid samples (suspended particulate matter (SPM) and sediment samples), respectively. Recoveries ranged from 52 (diethylphthalate (DEP)) to $116 \%$ (DBP) for water, from 54 (DEP) to $108 \%$ (estrone (E1)) for SPM, and from 62 (4-n-nonylphenol (4nNP)) to $117 \%$ (4- $n$-octylphenol (4nOP)) for sediment samples. Finally, with the minimization of reagents and energy, the proposed methods were applied to samples collected from Todos os Santos Bay (BTS), Bahia, Northeastern Brazil.
\end{abstract}

Keywords: alkylphenols, steroid hormones, phthalates, bisphenol A, plasticizers

\section{Introduction}

Coastal ecosystems play an important role in receiving hydrophobic contaminants from different routes. In general, marine areas are the final destination of pollutants from land runoff, atmospheric deposition, and discharges from industrial, agricultural, and domestic effluents. ${ }^{1-5}$ Due to their hydrophobic characteristics, once organic compounds enter into the water bodies, they tend to be preferentially associated with suspended particulate matter (SPM) and sediments as well as being absorbed by biota. ${ }^{6-12}$ This tendency is likely to be even more pronounced in marine waters due to their inherently high salt content. Those characteristics make the

*e-mail: gabriel.cotrim.souza@gmail.com; giseleor@ufba.br

†in memoriam. hydrophobic organic compounds easily migrate to other compartments, binding to organic matter., ${ }^{1,13-15}$ In turn, once in the biota, hydrophobic compounds may take part in the food web, circulating among different trophic levels as they may bioaccumulate and/or biomagnify.

Depending on the chemical structure and other physicochemical characteristics, hydrophobic organic compounds are likely to have different (eco)toxicological effects on wildlife and human health..$^{7,16-18}$ Indeed, there is a large group of hydrophobic organic chemicals known or suspected to cause some level of endocrine dysfunctions in living beings. They are classified as endocrine-disrupting compounds (EDCs), which have received increasing interest in the last decades due to their increasing occurrence and persistence in the environment. Some EDCs can bind to hormone receptors in organisms and disrupt regular 
hormone syntheses and metabolism. ${ }^{19}$ One such important group of hydrophobic organic compounds classified as EDCs are compounds largely utilized in the polymer industry as plasticizers: bisphenol A (BPA), phthalates, and alkylphenols. Another important EDC group is the natural (endogenous) or synthetic steroidal hormones (e.g., $17 \alpha$-ethynyl-estradiol (EE2)). These species are considered to be ubiquitous in all environmental compartments. ${ }^{20,21}$

BPA is one of the highest production chemicals globally, with a total production of over 3.7 million tons per year. ${ }^{22}$ The global bisphenol A market is projected to reach approximately 7,348,000 tons by the end of 2023, increasing around $3 \%$ per year. Accordingly, the global BPA market is estimated to have reached US\$ 20 billion by the end of $2020 .{ }^{23}$ Considering plasticizers as a whole, estimates from 2018 show that about 7.45 million tons of plasticizers were used for the plastic products industry globally. Projections for the global plasticizers market will continue to grow, and the consumption will reach a volume of 10.5 million tons per year in $2026 .{ }^{24}$ These expressive numbers show that the EDCs are likely to be potentially found in appreciable levels in the environment.

In turn, EE2, a synthetic analog of natural estrogen $17 \beta$-estradiol (E2), is extensively used in hormonal contraceptives and estrogen replacement therapies. EE2, together with E2, estrone (E1), and estriol (E3), are also EDCs and have been found in sewage, riverine, estuarine, and marine waters. ${ }^{19,25}$

The measurement of EDCs in environmental samples is challenging due to their low concentration levels, typically found at sub-ng $\mathrm{L}^{-1}$ in waters and low $\mathrm{ng} \mathrm{g}^{-1}$ to $\mu \mathrm{g} \mathrm{g}^{-1}$ in suspended particles and sediments. ${ }^{20,21,26,27}$ For this reason, research on the occurrence, distribution, and fate of EDCs, as well as their (eco)toxicology in the aquatic systems, is still limited. Hence, sensitive, versatile, comprehensive, and selective analytical methodologies for determining EDCs in the environment are highly required and primordial for a better understanding of their fate and impacts in the environment. There are also other desirable characteristics for ideal analytical methods, such as fastness, simplicity, competitive economic aspects, and the low consumption of reagents and, consequently, low waste generation (as suggested by the Principles of Green Analytical Chemistry). ${ }^{26-29}$ However, in real-world conditions, some of those characteristics mentioned above are hard to achieve due to the lack of information or requirements of sophisticated instrumentation and highlytrained personnel needed for analysis and the associated usual high costs.

Concerning sample preparation methods, depending on the complexity of environmental matrices (i.e., water, suspended particulate matter, and sediment, among others), many different isolations, preconcentration, and clean-up steps are proposed in the literature. ${ }^{26-28,30-33}$ For analysis of aqueous samples, most of the sample preparation methods often employ solid-phase extraction (SPE), ${ }^{10,20,21,26,34,35}$ liquid-phase microextraction (LPME), ${ }^{33,36,37}$ and stir bar sorptive extraction (SBSE) ${ }^{29}$ In terms of sample complexity, sample preparation methods for solid environmental matrices become more difficult and troublesome. ${ }^{27}$ Solid sample preparation methods generally include ultrasoundassisted extraction (USE), ${ }^{38-40}$ microwave-assisted extraction (MAE), ${ }^{41}$ and pressurized liquid extraction (PLE), ${ }^{42}$ followed by one or more of the clean-up steps. Cleaning up is often done by SPE, commonly employing C18, silica, or Florisil cartridges. ${ }^{27}$ Nonetheless, for each technique, both advantages and disadvantages are considered in analyzing EDCs in environmental matrices. Indeed, the authors kindly suggest to the readers to refer to very interesting reviews published by Salgueiro-González et al. ${ }^{26,27}$ in order to deal with those in more details, since they are out of the scope of the present study.

EDC analysis is largely done by either gas chromatography coupled to flame ionization (GC-FID) ${ }^{9,26,27}$ or mass spectrometer (GC-MS or GC-MS/MS) (13,26,27 $^{9}$ detectors as well as liquid chromatography with ultraviolet (LC-UV), ${ }^{9,10}$ fluorescence (LC-FLD), ${ }^{9,10}$ or mass spectrometer (LC-MS, LC-MS/MS) ${ }^{9,12}$ detectors. Although GC-MS is a robust instrumental technique with adequately low limits of detection (LOD) and limits of quantification (LOQ) for determinations of plasticizers and hormones in environmental samples, it is still necessary to have a derivatization step in the procedure. This is due to the fact that separation is improved when silylation or acylation is done in order to derivatize the hydroxyl groups of the EDCs. This step is important for reducing polarity, increasing volatility, and thermal stability of the analytes, all interesting characteristics for GC-based analyses. However, derivatization may generally result in important analyte losses during analyses (i.e., no derivatization reaction is able to reach a $100 \%$ yield), which is not affordable in most situations when determining EDCs in environmental complex matrices. On the other hand, liquid chromatography-based methods generally do not require a derivatization step, which could potentially simplify and become a faster way for the EDCs determination (and reflect in lower LOD/LOQ values). ${ }^{10,20,21,26-28,30,34,35,43-48}$

This study aimed to develop sensitive, simple, reliable, and cost-effective analytical methodologies for the determination of plasticizers and steroid hormones in marine water, suspended particulate matter (SPM), and sediment samples by ultrafast liquid chromatography 
coupled to a photodiode array (PDA) and fluorescence detectors (UFLC-PDA-FLD). In this work, we chose to study fourteen target EDCs, namely BPA, 4- $n$-octylphenol (4nOP), 4-tert-octylphenol (4tOP), 4- $n$-nonylphenol (4nNP), E1, E2, E3, EE2, dimethylphthalate (DMP), diethylphthalate (DEP), dibutylphthalate (DBP), butylbenzylphthalate (BBP), di-(2-ethylhexyl)phthalate (DEHP), and di-n-octylphthalate (DnOP), which are widely distributed in the aquatic systems. Furthermore, we optimized and validated our methods according to International Union of Pure and Applied Chemistry (IUPAC) guidelines ${ }^{49-52}$ regarding response function, linear range, linearity, LOD, LOQ, selectivity, precision, matrix effect, accuracy, and application to real samples. Indeed, the proposed methods were successfully applied to coastal waters, SPM, and sediment samples collected from Todos os Santos Bay (BTS), Bahia, Northeastern Brazil.

\section{Experimental}

\section{Materials and instruments}

All solutions, standard solutions, and eluents were done with ultrapure water (resistivity higher than $18.2 \mathrm{M} \Omega \mathrm{cm}$, Milli-Q-Plus, Millipore, USA). Solvents used in this study, such as acetonitrile ( $\mathrm{ACN})$, methanol $(\mathrm{MeOH})$, and dichloromethane (DCM), were chromatographic and spectroscopic grade, purchased from J. T. Baker (USA). We also used hydrochloric acid $37 \%\left(\mathrm{~m} \mathrm{~m}^{-1}\right)$ (P. A. grade, Merck, Germany) and glacial acetic acid $\left(99.9 \% \mathrm{~m} \mathrm{~m}^{-1}\right.$, J. T. Baker, USA).

EDC analytical standards were bisphenol A (BPA) (99\%, Sigma-Aldrich, USA), 4- $n$-nonylphenol (4nNP) (99\%, Sigma-Aldrich, USA), 4-t-octylphenol (4tOP) (99\%, Sigma-Aldrich, USA), estrone (E1) (99\%, Sigma-Aldrich, USA), 17 $\beta$-estradiol (E2) (99\%, SigmaAldrich, USA), ethynylestradiol (EE2) (99\%, SigmaAldrich, USA), estriol (E3) (98\%, Sigma-Aldrich, USA), dimethylphthalate (DMP) (99\%, SAFC Supply Solutions, USA), diethylphthalate (DEP) (98\%, SAFC Supply Solutions, USA), butylbenzylphthalate (BBP) (98\%, SigmaAldrich, USA), di- $n$-butylphthalate (DBP) (99\%, SigmaAldrich, USA), di-(2-ethylhexyl)phthalate (DEHP) (99\%, Sigma-Aldrich, USA), and di- $n$-octylphthalate (DnOP) (98\%, Sigma-Aldrich, USA). Stock solutions (1000 $\mathrm{mg} \mathrm{L}^{-1}$ ) of each chemical were prepared in methanol and kept in aluminum foil-wrapped amber flasks in the dark, and in the refrigerator (at $4^{\circ} \mathrm{C}$ ), up to 3 months. Standard solutions were prepared by successive dilutions from the stock solutions. Quantifications were done using 10 concentration levels external calibration curves. Details regarding quality assurance and quality control (QA/QC) procedures are presented in the Supplementary Information (SI) section.

EDC determinations were done by using an ultrafast liquid chromatograph (UFLC, LC-20ADXR Prominence, Shimadzu, Japan) equipped with high-pressure dual pumps (LC-20ADXR, Shimadzu, Japan), a degassing unit (DGU-20A3, Prominence, Shimadzu, Japan), an autosampler (SIL-20AXR, Prominence, Shimadzu, Japan), a column oven (CTO-20A, Prominence, Shimadzu, Japan), a photodiode array detector (PDA, SPD-M20A, Prominence, Shimadzu, Japan) and a fluorescence detector (FLD, RF-20A, Prominence, Shimadzu, Japan). Separation was carried out in a Shim-pack XR-ODS column $(150 \times 2 \mathrm{~mm}, 2.2 \mu \mathrm{m}$ particle size, and $8 \mathrm{~nm}$ pore size $)$.

\section{Sample collection}

We collected coastal waters, SPM, and sediments from Todos os Santos Bay, Bahia, Brazil, to develop and validate the analytical methods. Considering there are no commercially available standard reference materials (SRM) for EDCs, for the method development, we collected waters from the Ondina beach (OND), Salvador, Bahia (Figure 1). This beach was chosen for collecting water samples at the method development and validation steps since it is close to the University, and it is known ${ }^{10}$ this site has EDCs levels below the method LOD. In order to proceed with the method development, water samples were enriched with a known amount of the EDCs standards. We collected water samples from $10 \mathrm{~cm}$ below the surface into $4 \mathrm{~L}$ amber bottles previously cleaned, as stated in the QA/QC description (presented in SI section). Prior to collection, the bottles were rinsed three times with the ambient water sample. After collection, samples were kept in ice and rapidly transported to the laboratory. In the lab, the water samples were vacuum filtered (vacuum pump WP611560, Millipore Corporation, USA) through glass fiber filters (calcinated at $400{ }^{\circ} \mathrm{C}$ for $4 \mathrm{~h}, 47 \mathrm{~mm}$ diameter, $0.7 \mu \mathrm{m}$ pore size, Whatmann, UK). The dissolved fractions of the water samples were analyzed immediately after preparation.

The samples for suspended particulate matter (SPM) were collected from Ribeira bay (RIB) (Figure 1), a site that has relatively large amounts of SPM. The amount of filtered water varied according to the SPM mass on filters in order to obtain filter masses of at least ca. $15 \mathrm{mg}$ dried weight $(\mathrm{dw})$. Filters were dried at room temperature in desiccators until they reach constant masses and then kept in the freezer for up to 3 months until analyses.

For sediments, tests were performed using a sample previously collected from Paraguaçu Estuary (sample 4) ${ }^{52}$ that presents low EDC concentrations. Surface sediment 


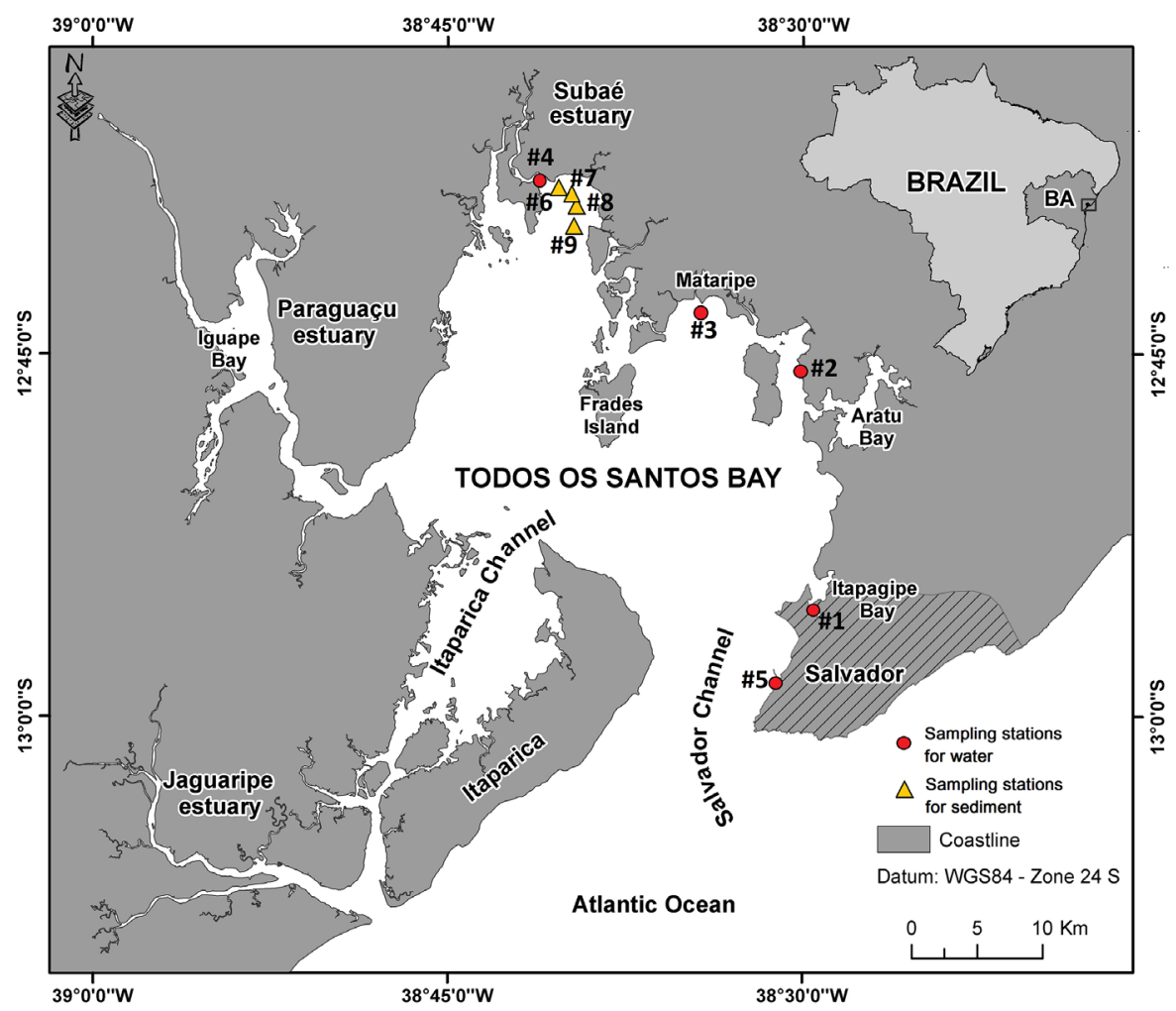

Figure 1. Sampling stations for water and SPM collection ((1) ALA, (2) CAB, (3) MAT, (4) SFC, and (5) TMA) and sediments (6, 7, 8 and 9 in the Subaé Estuary) in Todos os Santos Bay, Bahia, Brazil.

(first $5 \mathrm{~cm}$ ) was collected by using a Van Veen dredge. The sample was collected with a metal spoon covered with previously decontaminated aluminum foil, stored in DCM-cleaned and calcinated aluminum containers, and kept in the freezer until analysis.

Water and SPM $(n=3)$ simple samples from several localities along the Todos os Santos Bay, namely: Alagados (ALA), Caboto (CAB), Mataripe (MAT), São Francisco do Conde (SFC), and Terminal Marítimo (TMA) (Figure 1), were used for method validation. For sediments, composite samples were collected from the Subaé Estuary (Figure 1). These samples were collected as described above and were analyzed according to the optimized procedure for EDCs.

Development, optimization, and validation of an analytical method for EDCs

Analytical method development was done through univariate procedures. For this purpose, we considered the following reasoning: $(i)$ extraction of EDCs in coastal waters (dissolved fraction) by using SPE as sample preparation method, (ii) extraction of EDCs in SPM by microwave-assisted extraction (MAE) and ultrasoundassisted extraction (UAE), (iii) extraction of EDCs in sediments by USE, and (iv) separation and determination of EDCs by UFLC-PDA-FLD. Validation was done following the IUPAC recommendations for calibration curves, repeatability, selectivity, sample matrix effect, precision, accuracy, limit of detection (LOD), limit of quantification (LOQ), and analysis of real samples (which were collected in Todos os Santos Bay, Bahia, Brazil). ${ }^{48-51,53-57}$

\section{Water sample preparation}

The preconcentration apparatus used for coastal waters sample preparation is a modified version of the apparatus proposed by Sodré et al. ${ }^{58}$ This system can preconcentrate up to $4 \mathrm{~L}$ water samples through commercial SPE cartridges. It is composed by a set of 4 SPE preconcentration lines manufactured with polytetrafluoroethylene (PTFE) pieces, sphere valves, metal nipples, and stainless-steel tube adaptors. This SPE set is connected to a reservoir to collect water coming through SPE cartridges by using a vacuum pump (Figure S1, SI section).

We tested two types of cartridges: C18 $(6 \mathrm{~mL}$ polypropylene tubes with $1 \mathrm{~g}$ adsorbent, Supelco, USA) and Oasis HLB ( $6 \mathrm{~mL}$ glass tubes with $200 \mathrm{mg}$ adsorbent, Waters, USA). In regard to the Oasis HLB cartridges, firstly we did not condition them before use (as instructed by the manufacturers in their certificate). In this way, analyte recovery tests using Oasis HLB cartridges were performed without any prior conditioning, and even then, the analytes were poorly retained. So, after that, we tested 
different forms of conditioning for both cartridges. For each type of cartridge, we carried out four different SPE cartridge conditioning tests: (i) $15 \mathrm{~mL}$ ACN/MeOH (1:1), (ii) $15 \mathrm{~mL}$ ACN followed by $15 \mathrm{~mL} \mathrm{MeOH,} \mathrm{(iii)} 15 \mathrm{~mL}$ acetone followed $15 \mathrm{~mL} \mathrm{MeOH}$, and (iv) $15 \mathrm{~mL} \mathrm{MeOH}$. Each test was done at $1.5 \mathrm{~mL} \mathrm{~min}^{-1}$ and then $15 \mathrm{~mL}$ ultrapure water (also at $1.5 \mathrm{~mL} \mathrm{~min}^{-1}$ ). At this step, we used coastal water samples enriched with a final concentration of $50 \mu \mathrm{g} \mathrm{L}^{-1}$ of E2, E3, EE2, BPA, 4nOP, 4tOP, and 4nNP, $250 \mu \mathrm{g} \mathrm{L}^{-1}$ final concentration for $\mathrm{E} 1$, and $10 \mathrm{mg} \mathrm{L}^{-1}$ final concentration for each phthalate. Then, we passed the $1 \mathrm{~L}$ water sample, which is the preconcentration step by itself. After that, we rinsed the cartridges with $15 \mathrm{~mL}$ ultrapure water to remove sea salt and then dried them at room temperature. For eluting the EDCs from cartridges, we tested a fractionated elution ( 2 times of $2 \mathrm{~mL}$ followed by 4 times of $1 \mathrm{~mL} \mathrm{MeOH})^{10}$ and analyzed them as separate fractions. We observed the complete EDCs removal from the cartridge after elution of $5 \mathrm{~mL} \mathrm{MeOH}$. In order to assure EDCs' complete elution, cartridges were eluted with $6 \mathrm{~mL}$ $\mathrm{MeOH}$. Next, the extracts were filtered through syringe filter Millex units (cellulose membrane, $0.22 \mu \mathrm{m}$ pore size, $15 \mathrm{~mm}$ diameter, Millipore Corporation, Bedford, USA). Next, the extracts were injected into a UFLC-PDA-FLD system. After the tests with cartridges and the conditioning method, we also assessed if acidifying the water samples would improve extraction. We tested $\mathrm{pH}$ values at $1,2,4$, and 6 by using an $\mathrm{HCl} 1.0 \mathrm{~mol} \mathrm{~L}^{-1}$ solution to adjust the $\mathrm{pH}$ of the enriched water samples. All tests were done in triplicates.

\section{SPM sample preparation}

We tested SPM extractions through microwave-assisted extraction (MAE) (Multiwave Pro, Anton Paar, USA) and ultrasound-assisted extraction (USE) (ultrasonic bath, model T760DH, Elma, Germany) procedures. In both cases, we tested 6 different extracting solvents: ACN 100\%, DCM 100\%, ACN:DCM 1:1 ( $\left.\mathrm{v} \mathrm{v}^{-1}\right)$, ACN:DCM 1:3 ( $\left.\mathrm{v} \mathrm{v}^{-1}\right)$, ACN:DCM 3:1 ( $\left.\mathrm{v} \mathrm{v}^{-1}\right)$, and ACN:MeOH 1:1 ( $\left.\mathrm{v} \mathrm{v}^{-1}\right)$.

For MAE, we tested each extracting solution with 3 different heating programming: $(i)$ rising from room temperature to $60{ }^{\circ} \mathrm{C}$ for $10 \mathrm{~min}$, staying at $60{ }^{\circ} \mathrm{C}$ for $30 \mathrm{~min}$, and cooling back to room temperature in $20 \mathrm{~min}$ (total runtime: $60 \mathrm{~min}$ ); (ii) rising from room temperature to $80{ }^{\circ} \mathrm{C}$ for $10 \mathrm{~min}$, staying at $80{ }^{\circ} \mathrm{C}$ for $30 \mathrm{~min}$, and cooling back to room temperature in $20 \mathrm{~min}$ (total runtime: $60 \mathrm{~min}$ ); and (iii) rising from room temperature to $110^{\circ} \mathrm{C}$ for $10 \mathrm{~min}$, staying at $110{ }^{\circ} \mathrm{C}$ for $30 \mathrm{~min}$, and cooling back to room temperature in $20 \mathrm{~min}$ (total runtime: $60 \mathrm{~min}$ ). Thus, we tested 3 extraction times $(10,20$, and $30 \mathrm{~min})$ at $120 \mathrm{~W}$ in the USE experiments.
During MAE and USE tests, SPM filters were cut into small pieces with cleaned scissors and either transferred to extraction tubes (for MAE) or $10 \mathrm{~mL}$ amber flasks (for USE). For both procedures, $7 \mathrm{~mL}$ of extraction solvents were added on top of the filter pieces. This extraction solvent volume was set by the minimum volume of MAE as determined by the manufacturer and in order to keep the same solvent-to-filter proportion in USE. After extraction, samples were centrifuged at $2000 \mathrm{rpm}$ for $10 \mathrm{~min}$ and the supernatants were collected. ${ }^{59}$ Next, we cleaned up the extracts by passing them through Florisil cartridges $(3 \mathrm{~mL}$, $500 \mathrm{mg}$ adsorbent mass, Agilent Technologies, USA) ${ }^{60}$ previously conditioned with $2 \mathrm{~mL} \mathrm{MeOH}$. Following, the extracts were filtered through syringe filter Millex units (cellulose membrane, $0.22 \mu \mathrm{m}$ pore size, $15 \mathrm{~mm}$ diameter, Millipore Corporation, Bedford, USA) and directly transferred to vials to be then injected into the UFLCPDA-FLD system. All solvent tests and blank tests were done in triplicate.

\section{Sediment sample preparation}

All the frozen sediment samples were lyophilized (lyophilizer Alpha 1-4 LDplus, Christ, Germany) and ground with a ball mill (8000 D, SPex sample prep., USA). An aliquot of $1 \mathrm{~g}$ sediment mass was extracted with $7 \mathrm{~mL}$ of solvent extraction mix, which presented the best results for extractions. Then, the sediment extract was cleaned up and analyzed by the best SPM results procedure. All experiments and blanks were done in triplicates. After optimizing the sample preparation procedures for water, SPM, and sediment matrices, we performed the recovery tests. We added an $\mathrm{N}_{2}$ stream extract drying step for these tests, followed by an extract resuspension to 500, 250, and $500 \mu \mathrm{L}$ of $\mathrm{MeOH}$ for water, SPM, and sediment samples, respectively.

Development and validation of a chromatographic method by UFLC-PDA-FLD

The significant differences in phthalates' physical and chemical characteristics compared to the other EDCs led us to develop two different chromatographic methods to determine the 14 EDCs in this study. The first method was adjusted for the phthalates and alkylphenols, and the second one was used for the steroid hormones and BPA. Both methods used the same column (Shim-pack XR-ODS, $2 \mathrm{~mm}$ inner diameter, $150 \mathrm{~mm}$ length, $2.2 \mu \mathrm{m}$ particle size, and $8 \mathrm{~nm}$ pore size). For each method, we tested: ( $i$ ) different eluents, (ii) different eluent gradient programming, (iii) variation in the eluent flowrate, and (iv) variation of the column temperature.

In evaluating different eluents, we tested two sets of binary eluents: methanol and acidified ultrapure water 
$\left(2 \% \mathrm{v} \mathrm{v}^{-1}\right.$ acetic acid) and acetonitrile and acidified ultrapure water ( $2 \% \mathrm{v} \mathrm{v}^{-1}$ acetic acid). Individual and mix analytical standards were injected for each eluent system in order to adjust the best eluent gradient programming. The best separation condition was obtained after the tests with the gradient programming and the retention time for each compound. After that, tests were performed varying the eluent flowrate from 0.1 to $0.4 \mathrm{~mL} \mathrm{~min}^{-1}$, by incrementing $0.05 \mathrm{~mL} \mathrm{~min}^{-1}$ at a time.

We also carried out a range of tests regarding the variation of the column temperature. We assessed temperatures from 40 to $60{ }^{\circ} \mathrm{C}$, by incrementing $5{ }^{\circ} \mathrm{C}$ per time. Detection of steroid hormones, BPA, and alkylphenols was done by fluorescence detector set at $\lambda_{\text {exc }}=208 \mathrm{~nm}$ and $\lambda_{\mathrm{em}}=306 \mathrm{~nm}^{10,61}$ while PDA detected phthalates at $\lambda=245 \mathrm{~nm}$ (wavelength which we obtained the highest detector signal intensity). We used external calibration curves with 10 concentration levels, such as $1.0-50 \mu \mathrm{g} \mathrm{L}^{-1}$ (E3, BPA, E2, and EE2), 5.0-250 $\mu \mathrm{g} \mathrm{L}-1$ (E1), 2.5-50 $\mu \mathrm{g} \mathrm{L}-1$ (4tOP, 4nOP, and 4nNP) and 200-10,000 $\mu \mathrm{g} \mathrm{L}^{-1}$ (DMP, DEP, BBP, DBP, DEHP, and DnOP). Each standard was injected in triplicate.

\section{Results and Discussion}

\section{Sample preparation}

Sample preconcentration using coastal waters started by testing two types of SPE cartridges (Oasis HLB and C18), followed by the cartridge conditioning step, and then the sample acidification test. Recovery levels are presented in Table 1.

The best recovery levels were reached using $\mathrm{C} 18$ cartridges conditioned with $15 \mathrm{mLACN}$ followed by $15 \mathrm{~mL}$ $\mathrm{MeOH}$. Thus, even though Oasis HLB cartridges have been developed specifically for EDCs, they did not show better results than $\mathrm{C} 18$ cartridges. It may be due to the fact $\mathrm{C} 18$ cartridges present less polarity and more active sites than the Oasis HLB cartridges (copolymer of $n$-vinylpyrrolidone and divinylbenzene), favoring better retention of the studied low polarity EDCs. In general, reverse phase functionalized silica SPE cartridges are generally conditioned with water miscible-solvents, such as methanol. ${ }^{62-66}$ Within this type of adsorbent, methanol works wetting its surface and penetrating the alkyl bonds, making active sites available for interactions with the analytes. In turn, acetonitrile is used to improve the adsorbent conditioning by removing the possible interferents present in the cartridges with more efficiency.

Rinsing cartridges with ultrapure water after the salted water samples concentration step is very important to avoid chromatograph problems, such as column pore obstruction or salt precipitation in the injector. Additionally, not removing the salt content before sample elution may cause analyte losses due to the salting-out effect when eluting the sample into the vial, resulting in low recovery levels.

In the attempt of improving recoveries and preserving samples after field collection and filtration, we tested sample acidification at different $\mathrm{pH}$ values. The chemical equilibria of EDCs in aqueous solutions can be controlled

Table 1. Recovery levels \pm one standard deviation, for SPE cartridge conditioning tests and standard-enriched seawater samples

\begin{tabular}{|c|c|c|c|c|c|c|c|c|}
\hline \multirow{3}{*}{ Compound } & \multicolumn{8}{|c|}{ Recovery level \pm one standard deviation / \% } \\
\hline & \multicolumn{4}{|c|}{ Oasis HLB } & \multicolumn{4}{|c|}{$\mathrm{C} 18$} \\
\hline & $i$ & $i i$ & $i i i$ & $i v$ & $i$ & $i i$ & $i i i$ & iv \\
\hline$\overline{\mathrm{E} 3}$ & $95 \pm 4.9$ & $111 \pm 4.8$ & $95 \pm 3.8$ & nd & $12 \pm 1.5$ & $86 \pm 10$ & $115 \pm 1.1$ & $11 \pm 1.1$ \\
\hline BPA & $89 \pm 6.6$ & $99 \pm 0.081$ & $102 \pm 3.0$ & nd & $47 \pm 4.0$ & $97 \pm 4.0$ & $112 \pm 1.4$ & $47 \pm 1.9$ \\
\hline E2 & $87 \pm 1.9$ & $98 \pm 9.0$ & $108 \pm 2.0$ & nd & $105 \pm 0.77$ & $99 \pm 7.6$ & $112 \pm 6.9$ & $99 \pm 6.4$ \\
\hline $\mathrm{EE} 2$ & $101 \pm 3.1$ & $101 \pm 4.0$ & $103 \pm 3.4$ & nd & $96 \pm 0.12$ & $97 \pm 2.3$ & $104 \pm 0.055$ & $92 \pm 3.1$ \\
\hline E1 & $107 \pm 3.7$ & $84 \pm 3.4$ & $89 \pm 4.6$ & nd & $99 \pm 1.0$ & $97 \pm 3.8$ & $101 \pm 0.091$ & $94 \pm 0.71$ \\
\hline $4 \mathrm{tOP}$ & $78 \pm 3.2$ & $62 \pm 4.3$ & $88 \pm 4.0$ & nd & $85 \pm 3.0$ & $85 \pm 2.0$ & $72 \pm 0.18$ & $75 \pm 9.9$ \\
\hline $4 \mathrm{nOP}$ & $49 \pm 1.3$ & nd & $85 \pm 4.7$ & nd & $70 \pm 0.078$ & $92 \pm 5.2$ & $51 \pm 3.3$ & $57 \pm 6.7$ \\
\hline $4 \mathrm{nNP}$ & nd & nd & $53 \pm 1.5$ & nd & $25 \pm 4.9$ & $63 \pm 3.2$ & $26 \pm 12.2$ & $13 \pm 1.3$ \\
\hline DMP & $114 \pm 3.1$ & $20 \pm 0.76$ & $67 \pm 5.2$ & nd & $41 \pm 2.7$ & $68 \pm 4.7$ & $49 \pm 3.2$ & $32 \pm 1.4$ \\
\hline DEP & $102 \pm 7.8$ & $36 \pm 1.6$ & $81 \pm 6.5$ & nd & $71 \pm 8.6$ & $89 \pm 5.2$ & $70 \pm 0.37$ & $52 \pm 6.3$ \\
\hline $\mathrm{BBP}$ & $75 \pm 7.7$ & $78 \pm 0.70$ & $89 \pm 4.0$ & nd & $82 \pm 1.8$ & $84 \pm 3.6$ & $87 \pm 2.1$ & $82 \pm 2.2$ \\
\hline DBP & $89 \pm 12$ & $83 \pm 3.1$ & $96 \pm 3.7$ & nd & $90 \pm 0.62$ & $92 \pm 4.8$ & $90 \pm 1.9$ & $85 \pm 6.2$ \\
\hline DEHP & $40 \pm 3.5$ & $36 \pm 2.7$ & $34 \pm 3.4$ & nd & $35 \pm 0.53$ & $86 \pm 5.3$ & $85 \pm 2.4$ & $40 \pm 2.6$ \\
\hline DnOP & $33 \pm 4.3$ & $32 \pm 3.6$ & $29 \pm 1.9$ & nd & $35 \pm 0.60$ & $91 \pm 3.5$ & $84 \pm 3.0$ & $41 \pm 2.8$ \\
\hline
\end{tabular}

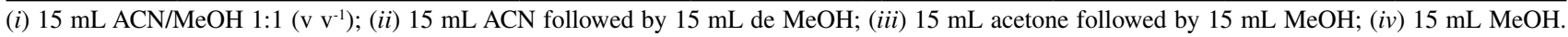
E3: estriol; BPA: bisphenol A; E2: 17 $\beta$-estradiol; EE2: ethynylestradiol; E1: estrone; 4tOP: 4-t-octylphenol; 4nOP: 4- $n$-octylphenol; 4nNP: 4- $n$-nonylphenol; DMP: dimethylphthalate; DEP: diethylphthalate; BBP: butylbenzylphthalate; DBP: di- $n$-butylphthalate; DEHP: di-(2-ethylhexyl)phthalate; DnOP: di- $n$ octylphthalate; nd: not detected. 
by the $\mathrm{pH}$ of the media. In this equilibrium, at low $\mathrm{pH}$, the ionization of the hydroxyl group is suppressed, favoring the molecular form of the compound (i.e., the hydroxyl group remains protonated instead of donating the $\mathrm{H}^{+}$). In this way, the protonated form (the molecular form) of the EDCs interacts more effectively with the alkyl groups from the $\mathrm{C} 18$ cartridges and the chromatographic column. As a result, the best recoveries were reached at $\mathrm{pH} 2$ (Table S1, SI section). For the same reasons, we chose to work with acidified ultrapure water in the binary eluent system. By using acidified water in the eluent system, we could preserve eluents for a longer time and improve separation. Therefore, considering the presented results here, the optimized conditions for seawater sample preparation were: $1 \mathrm{~L}$ acidified seawater sample (at $\mathrm{pH} 2$ ), a preconcentration step with $\mathrm{C} 18$ cartridges, conditioning of the $\mathrm{C} 18$ cartridge with $15 \mathrm{~mL}$ ACN followed by $15 \mathrm{~mL} \mathrm{MeOH}$, salt removal by rinsing cartridges with $15 \mathrm{~mL}$ ultrapure water prior the EDCs elution, followed by analytes elution with $6 \mathrm{~mL} \mathrm{MeOH}$, and analysis by UFLC-PDA-FLD (Figure S2, SI section).

In order to establish the optimal conditions for SPM sample preparation, we experimented six extraction solvents (ACN 100\%, DCM 100\%, ACN:DCM 1:1 ( $\left.\mathrm{v} \mathrm{v}^{-1}\right)$, ACN:DCM 1:3 ( $\left.\mathrm{v} \mathrm{v}^{-1}\right)$, ACN:DCM 3:1 $\left(\mathrm{v} \mathrm{v}^{-1}\right)$, and ACN:MeOH 1:1 $\left.\left(\mathrm{v} \mathrm{v}^{-1}\right)\right)$ with MAE and USE. Results for MAE and USE are presented in Figures 2 and 3, respectively. Results for MAE (Figure 2) presented higher variability than USE, with lower recovery levels for DMP and DEP in all extracting solutions. Considering that DMP and DEP present high vapor pressures, they were probably lost by volatilization during the MAE procedure.
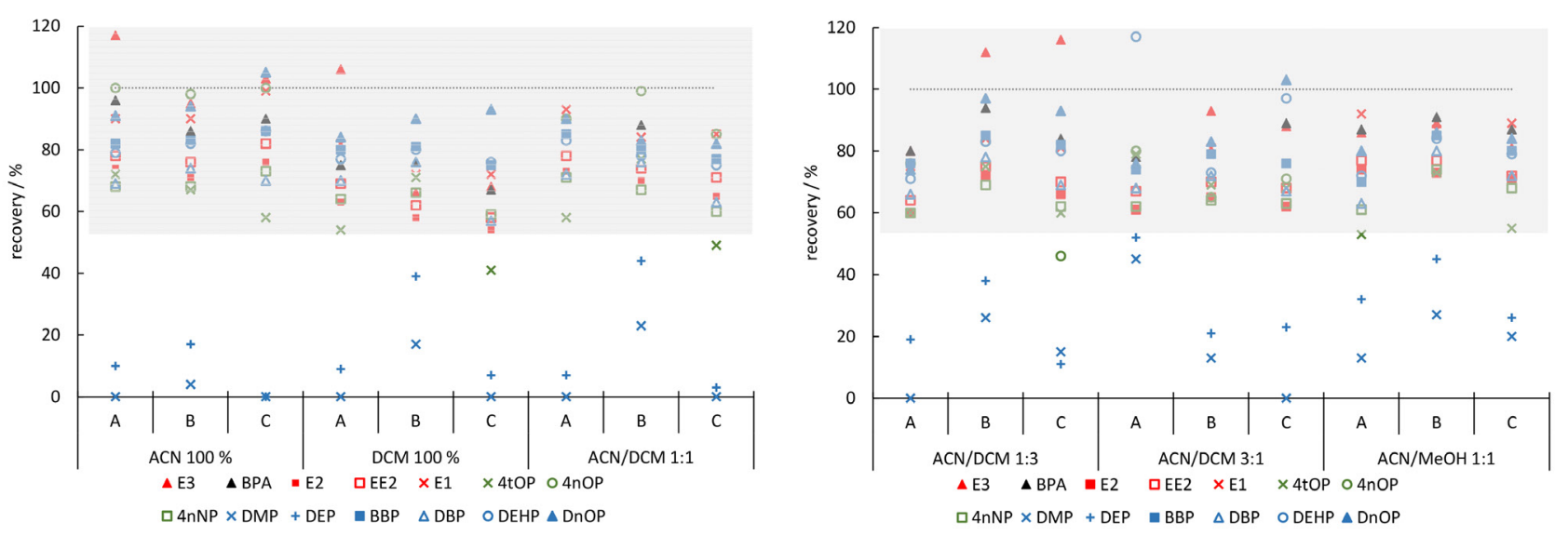

Figure 2. MAE results for EDCs extraction from SPM samples, employing six different extraction solutions. Results are recovery levels (\%) from standard addition* to SPM samples. *Final concentration of standards added to SPM samples: $50 \mu \mathrm{g} \mathrm{L}{ }^{-1}$ hormones, BPA, and alkylphenols; $250 \mu \mathrm{g} \mathrm{L}^{-1}$ estrone; and $10 \mathrm{mg} \mathrm{L}^{-1}$ phthalates. (A) $110{ }^{\circ} \mathrm{C}$; (B) $80{ }^{\circ} \mathrm{C}$; (C) $60{ }^{\circ} \mathrm{C}$. $(\mathrm{n}=3)$. Relative standard deviation (RSD) $\leq 7 \%$. The recovery limit range between $50-120 \%$ is highlighted in grey. It corresponds to the recovery accepted levels for complex sample matrices according to IUPAC. The dotted line presents the level corresponding to a recovery of $100 \%$.
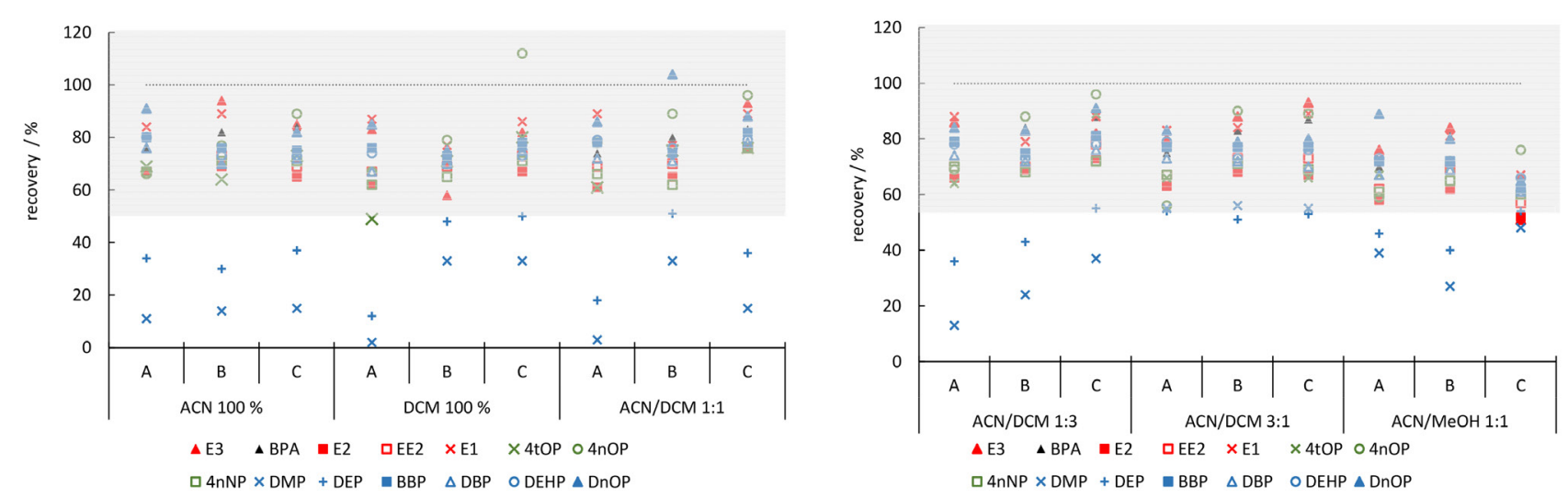

Figure 3. USE results for EDCs extraction from SPM samples, employing six different extraction solutions. Results are recovery levels (\%) from standard addition* to SPM samples. *Final concentration of standards added to SPM samples: $50 \mu \mathrm{g} \mathrm{L}{ }^{-1}$ hormones, BPA, and alkylphenols; $250 \mu \mathrm{g} \mathrm{L}^{-1}$ estrone; and $10 \mathrm{mg} \mathrm{L}^{-1}$ phthalates. (A) $10 \mathrm{~min}$; (B) $20 \mathrm{~min}$; (C) $30 \mathrm{~min}(\mathrm{n}=3)$. Relative standard deviation (RSD) $\leq 7 \%$. The recovery limit range between 50-120\% is highlighted in grey. It corresponds to the recovery accepted levels for complex sample matrices according to IUPAC. The dotted line presents the level corresponding to a recovery of $100 \%$. 
In addition, some compounds presented recovery levels higher than the accepted range (50-120\% for complex environmental samples), which is possibly due to the baseline signal increase for alkylphenols. The best results from MAE were reached with the ACN/DCM 1:3 $\left(\mathrm{v} \mathrm{v}^{-1}\right)$ mix with heating at $60{ }^{\circ} \mathrm{C}$, in which lower losses of the most volatile elements were observed.

In general, USE (Figure 3) presented better results than MAE, principally for DMP and DEP in almost every extracting solution. Among the extracting solutions evaluated, ACN/DCM 3:1 ( $\left.\mathrm{v} \mathrm{v}^{-1}\right)$ presented the best results for EDCs in SPM. It is probably because DCM presents good efficiency, dissolving non-polar species, whereas ACN provokes the decrease of the extracting mix vapor pressure and favors the dissolution of intermediary polarity compounds. Regarding the sonication time, there are no significant differences between the tests, with good results at $10 \mathrm{~min}$.

Considering the results presented in Figures 2 and 3, the optimal conditions for the SPM sample preparation were $7 \mathrm{~mL}$ ACN/DCM 3:1 $\left(\mathrm{v} \mathrm{v}^{-1}\right)$ under sonication $(120 \mathrm{~W})$ for $10 \mathrm{~min}$. Next, the extracts were centrifuged at $2000 \mathrm{rpm}$ for $10 \mathrm{~min}$, and then they were cleaned up through Florisil cartridges. Next, the extracts were filtered through Millex units, gently dried under $\mathrm{N}_{2}$ stream, and finally resuspended into $250 \mu \mathrm{L} \mathrm{MeOH}$. The final extracts were injected into the UFLC-PDA-FLD system afterward (Figure S2). Once having established the optimized sample preparation method for SPM, we applied the same procedure for the extraction of EDCs from sediments because SPM and sediment generally have similar compositions and will provide similar responses to the extraction processes. ${ }^{67}$

\section{Chromatographic method}

Firstly, we tried to develop an eluent gradient program that could satisfactorily separate the 14 EDCs in a single run with the best possible resolution. As a starting point, we considered the chromatographic conditions from Lisboa et al. ${ }^{10}$ since they also used an ultrafast liquid chromatograph, although in their study phthalates were not considered (only BPA, alkylphenols, and steroid hormones). However, considering in the present work we used a UFLC system with different specifications from Lisboa et al..$^{10}$ we could not repeat their separation conditions. Therefore, we optimized the gradient programs presented here. Initially, we used an eluent variation from $0 \%$ ACN to $100 \%$ ACN with acidified water (2\% acetic acid) by $20 \mathrm{~min}$. We separated the steroid hormones (E1, E2, E3, and EE2), BPA, and alkylphenols (4nOP, 4tOP, and $4 \mathrm{nNP}$ ) with fluorescence within this program detection and phthalates by PDA detection. By injecting individual standards, we identified their elution order and retention times. From modifications in the elution gradients, we could separate the 14 EDCs within 16 min. However, this elution gradient induced too much oscillation in the chromatogram baseline from the fluorescence detector interfering with some alkylphenols' detection. In order to overcome this situation, we decided to do two separated elution programming to enable good separations of all analytes, as stated in detail in Table S2 (SI section).

The optimization of the eluent programming, the flow rate, and the column temperature for each method was done univariately. For both methods, the chosen eluents were ACN and acidified ultrapure water ( $2 \%$ acetic acid) at $0.4 \mathrm{~mL} \mathrm{~min}{ }^{-1}$, and $60{ }^{\circ} \mathrm{C}$ as the column temperature. Method 1 is an isocratic eluent programming at 39\% $\mathrm{ACN}$ for $6.5 \mathrm{~min}$ total runtime for analysis of BPA and hormones, which are detected by fluorescence $\left(\lambda_{\mathrm{exc}}=208 \mathrm{~nm}\right.$ and $\left.\lambda_{\mathrm{em}}=306 \mathrm{~nm}\right)$. Method 2 is a gradient eluent programming, which starts at $66 \% \mathrm{ACN}$ and it is kept by $3 \mathrm{~min}$, then it rises from $66-71 \% \mathrm{ACN}$ until $3.8 \mathrm{~min}$, then it rises again from 71 to $100 \% \mathrm{ACN}$ during $1 \mathrm{~min}, 100 \% \mathrm{ACN}$ is kept during $2.2 \mathrm{~min}$, followed by a reduction from 100 to $66 \% \mathrm{ACN}$ during $0.5 \mathrm{~min}$. The total runtime was $10.5 \mathrm{~min}$. Alkylphenols' detection was done by fluorescence $\left(\lambda_{\text {exc }}=208 \mathrm{~nm}\right.$ and $\left.\lambda_{\text {em }}=306 \mathrm{~nm}\right)$ and phthalates detection was done by PDA $\left(\lambda_{\max }=245 \mathrm{~nm}\right)$. In Figure 4, there are standard solution chromatograms for EDCs (50 $\mu \mathrm{g} \mathrm{L}^{-1}$ alkylphenols, BPA, E2, E3, and EE2; $250 \mu \mathrm{g} \mathrm{L}{ }^{-1}$ for E1; and $10 \mathrm{mg} \mathrm{L}^{-1}$ for phthalates). For the method 1 , the elution order is $\mathrm{E} 3\left(\mathrm{t}_{\mathrm{R}}=1.45 \mathrm{~min}\right)$, BPA $\left(\mathrm{t}_{\mathrm{R}}=3.54 \mathrm{~min}\right), \mathrm{E} 2\left(\mathrm{t}_{\mathrm{R}}=4.49 \mathrm{~min}\right), \mathrm{EE} 2\left(\mathrm{t}_{\mathrm{R}}=5.76 \mathrm{~min}\right)$, and $E 1\left(t_{R}=6.17 \mathrm{~min}\right)$. In the method 2 the elution order is DMP $\left(t_{R}=1.21 \mathrm{~min}\right)$, DEP $\left(t_{R}=1.65 \mathrm{~min}\right)$, $4 \mathrm{tOP}\left(\mathrm{t}_{\mathrm{R}}=4.04 \mathrm{~min}\right), \mathrm{BBP}\left(\mathrm{t}_{\mathrm{R}}=4.19 \mathrm{~min}\right), \mathrm{DBP}$ $\left(\mathrm{t}_{\mathrm{R}}=4.72 \mathrm{~min}\right), 4 \mathrm{nOP}\left(\mathrm{t}_{\mathrm{R}}=6.18 \mathrm{~min}\right), 4 \mathrm{nNP}\left(\mathrm{t}_{\mathrm{R}}=8.15 \mathrm{~min}\right)$, $\operatorname{DEHP}\left(\mathrm{t}_{\mathrm{R}}=10.0 \mathrm{~min}\right)$, and DnOP $\left(\mathrm{t}_{\mathrm{R}}=10.2 \mathrm{~min}\right)$. The elution order and the respective retention time were obtained by injecting individual standards. Both methods show good peak separations with no co-elutions. Even though we needed two chromatographic methods, we could observe that these optimized methods were efficient to separate and detect the 14 EDCs by UFLC-PDA-FLD. The main advantages of these methods are ( $i$ ) no derivatization steps for determinations of BPA, hormones, and alkylphenols (which could reflect in losses and LOD/LOQ increase) when the analysis method would be GC-MS, (ii) reduction of sample contamination risk of phthalates from septa and other connections from the GC-MS instrumentation, (iii) shorter analysis time when compared to conventional LC methods, ${ }^{62,68-71}$ and (iv) drastic reduction of eluents and 

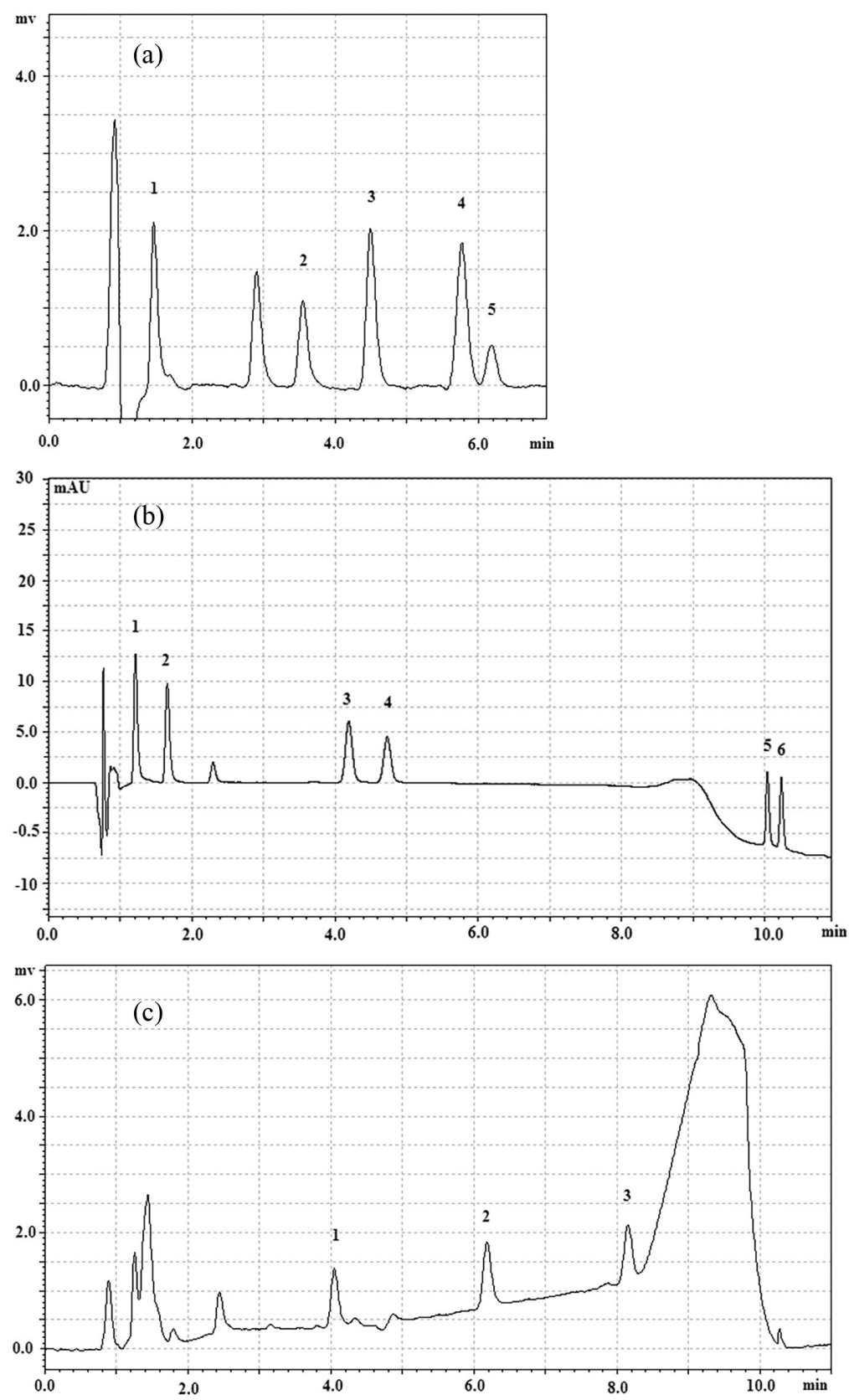

Figure 4. Chromatograms of $14 \mathrm{EDCs}$ standards, $50 \mu \mathrm{g} \mathrm{L}{ }^{-1} \mathrm{E} 2$, E3, EE2, BPA, and alkylphenols; $250 \mu \mathrm{g} \mathrm{L}^{-1} \mathrm{E} 1$; and $10 \mathrm{mg} \mathrm{L}^{-1}$ phthalates. (a) Peak 1: E3 (1.45 min), peak 2: BPA (3.54 min), peak 3: E2 (4.49 min), peak 4: EE2 (5.76 min), and peak 5: E1 (6.17 min) by method 1. (b) Peak 1: 4tOP (4.04 min), peak 2: 4nOP (6.18 min), and peak 3: 4nNP (8.15 min) by method 2 and FLD. (c) Peak 1: DMP (1.21 min), peak 2: DEP (1.65 min), peak 3: BBP (4.19 min), peak 4: DBP (4.72 $\mathrm{min})$, peak 5: DEHP (10.0 $\mathrm{min})$, and peak 6: DnOP (10.2 $\mathrm{min})$ by method 2 and PDA detector.

other solvents during analysis, which generates a much smaller amount of waste at the end.

\section{Method validation}

Method validation was carried out by following criteria suggested by IUPAC ${ }^{48-51}$ and also found in Domingos et al. ${ }^{53}$ Lisboa et al.,${ }^{10}$ Santos et al.,${ }^{54}$ and Nascimento et al ${ }^{55-57}$ In this way, we validated the proposed methods regarding calibration curve, limit of detection (LOD), limit of quantification (LOQ), linear range, linearity, accuracy, selectivity, matrix effect evaluation, precision, and tests with real samples. In addition, to assess selectivity of the chromatographic methods we investigated if there were interfering peaks around the analyte peaks when comparing a blank environmental sample chromatogram (a sample absent of analytes) with a standard-enriched environmental sample chromatogram. ${ }^{48-51,54,72-74}$ Figure S3 (SI section) shows comparisons between chromatograms of coastal water samples absent of analytes and standard-enriched. 
In turn, Figures S4-S7 (SI section) show comparisons among chromatograms of SPM and sediment samples absent of analytes and standard-enriched SPM and sediment samples. Figures S3-S7 show some ghost peaks in the chromatograms, but none of them interfere with the analytes' peaks detection. Therefore, the proposed methods are considered to be selective for the studied EDCs.

Linear regression equations were obtained by external calibration curves, and linearity was assessed based on the coefficient of determination, $R^{2}$. In turn, the linear range was considered to be ranged from the respective LOD for each compound to the highest injected standard concentration. As a result, a good linear fit was observed for the studied EDCs over the full range of the calibration curves, with $\mathrm{R}^{2}>0.995$ for all species (Table 2). Linearity and linear range of calibration curves have met the minimum criteria established by IUPAC for obtaining suitable adjustments and reliable results.

The LOD and the LOQ were calculated considering the data of the calibration curves..$^{52,53-57,73,74}$ Briefly, $\mathrm{LOD}=3 \times(\mathrm{s} / \mathrm{a})$ and $\mathrm{LOQ}=10 \times(\mathrm{s} / \mathrm{a})$, where "s" is the linear coefficient standard deviation and "a" is the angular coefficient from the respective analytical curve for a given compound. Then, the LOD and LOQ for the water were recalculated considering the nominal volume of $1.0 \mathrm{~L}$, including the $500 \mu \mathrm{L}$ concentration step during sample preparation, as shown in Table S2 (SI section). Accordingly, LOD and LOQ for solid samples were calculated by considering an average $1 \mathrm{~g} \mathrm{dw}$ sediment mass to $500 \mu \mathrm{L}$ of final extraction (Table 2). Method LOD values varied from $0.412 \mathrm{ng} \mathrm{L}^{-1}$ (4tOP) to $63.2 \mathrm{ng} \mathrm{L}^{-1}$ (DBP) for seawater and from 0.412 to $63.2 \mathrm{ng} \mathrm{g}^{-1} \mathrm{dw}$ for solid samples, respectively, to $4 \mathrm{tOP}$ and DBP. These LODs and LOQs for the determination of 14 EDCs in environmental samples are considered adequate since they are similar to those found in the literature (Tables S3-S4, SI section).

The sample matrix effect was evaluated by comparing the angular coefficient (a) from two linear regression curves made with and without standard additions. One set of the curves was made with 6 standard concentration levels added either to coastal water sample $\left(\mathrm{a}_{\text {standard }+ \text { water }}\right)$, to SPM sample matrix $\left(a_{\text {standard }+\mathrm{SPM}}\right)$, or sediment sample matrix $\left(\mathrm{a}_{\text {standard }+ \text { sediment }}\right)$. The second curve was done with standards dissolved in methanol $\left(\mathrm{a}_{\text {standard }}\right)$ and directly injected into the UFLC-PDA-FLD system. If there is no significant sample matrix effect in the analysis, the ratio $a_{\text {standard }+ \text { sample }} / a_{\text {standard }}$ should be close to 1 , and there would not need to make quantification by standard addition calibration curve, which is difficult and time-consuming. As presented in Table S5 (SI section), among all samples, some compounds (for

Table 2. Figures-of-the-merit for both optimized methods regarding the determination of 14 EDCs in seawater, SPM, and sediment samples. Results are expressed as $\mathrm{t}_{\mathrm{R}}$, linearity, linear range, instrument LOD, instrument LOQ, seawater LOD, seawater LOQ, solid samples LOD, and solid samples LOQ

\begin{tabular}{|c|c|c|c|c|c|c|c|c|c|c|c|}
\hline Method & Analyte & $t_{R} / \min$ & Calibration curve & $\begin{array}{l}\text { Linearity } \\
\left(\mathrm{R}^{2}\right)\end{array}$ & $\begin{array}{l}\text { Linear } \\
\text { range / } \\
\left(\mu \mathrm{g} \mathrm{L}^{-1}\right)\end{array}$ & $\begin{array}{l}\mathrm{LOD}^{\mathrm{a}} / \\
\left(\mu \mathrm{g} \mathrm{L}^{-1}\right)\end{array}$ & $\begin{array}{l}\mathrm{LOQ}^{\mathrm{a}} / \\
\left(\mathrm{ng} \mathrm{L}^{-1}\right)\end{array}$ & $\begin{array}{c}\text { Seawater } \\
\text { LOD }^{\mathrm{b}} / \\
\left(\mathrm{ng} \mathrm{L}^{-1}\right)\end{array}$ & $\begin{array}{c}\text { Seawater } \\
\mathrm{LOQ}^{\mathrm{b}} / \\
\left(\mathrm{ng} \mathrm{L} \mathrm{L}^{-1}\right)\end{array}$ & $\begin{array}{c}\text { Solid } \\
\text { samples } \\
\text { LOD }^{\mathrm{c}} / \\
\left(\mathrm{ng} \mathrm{g}^{-1} \mathrm{dw}\right)\end{array}$ & $\begin{array}{c}\text { Solid } \\
\text { samples } \\
\text { LOQ }^{\mathrm{c}} / \\
\left(\mathrm{ng} \mathrm{g}^{-1} \mathrm{dw}\right)\end{array}$ \\
\hline \multirow{5}{*}{1} & E3 & 1.45 & $y=313 x+24.2$ & 0.9973 & $1.36-50$ & 1.36 & 4.52 & 0.678 & 2.26 & 0.678 & 2.26 \\
\hline & BPA & 3.54 & $y=210 x-149$ & 0.9955 & $1.52-50$ & 1.52 & 5.06 & 0.759 & 2.53 & 0.759 & 2.53 \\
\hline & E2 & 4.49 & $y=386 x-72.3$ & 0.9991 & $1.63-50$ & 1.63 & 5.44 & 0.816 & 2.72 & 0.816 & 2.72 \\
\hline & EE2 & 5.76 & $y=404 x+95.3$ & 0.9992 & $1.30-50$ & 1.30 & 4.34 & 0.652 & 2.17 & 0.652 & 2.17 \\
\hline & E1 & 6.17 & $y=25.4 x+65.3$ & 0.9971 & $7.98-250$ & 7.98 & 26.6 & 3.99 & 13.3 & 3.99 & 13.3 \\
\hline \multirow{9}{*}{2} & $4 \mathrm{tOP}$ & 4.04 & $y=190 x-161$ & 0.9981 & $1.30-50$ & 1.30 & 4.33 & 0.412 & 1.37 & 0.412 & 1.37 \\
\hline & $4 \mathrm{nOP}$ & 6.18 & $y=139 x-13.3$ & 0.9992 & $0.825-50$ & 0.825 & 2.75 & 0.649 & 2.16 & 0.649 & 2.16 \\
\hline & $4 \mathrm{nNP}$ & 8.15 & $y=145 x-251$ & 0.9989 & $1.01-50$ & 1.01 & 3.36 & 0.503 & 1.68 & 0.503 & 1.68 \\
\hline & DMP & 1.21 & $y=5.03 x+39$ & 0.9998 & $81.6-10000$ & 81.6 & 272 & 40.8 & 136 & 40.8 & 136 \\
\hline & DEP & 1.65 & $y=4.10 x+111$ & 0.9997 & $90.5-10000$ & 90.5 & 302 & 45.2 & 151 & 45.2 & 151 \\
\hline & $\mathrm{BBP}$ & 4.19 & $y=3.86 x+121$ & 0.9995 & $117-10000$ & 117 & 389 & 58.4 & 195 & 58.4 & 195 \\
\hline & DBP & 4.72 & $y=2.98 x+289$ & 0.9994 & $126-10000$ & 126 & 422 & 63.2 & 211 & 63.2 & 211 \\
\hline & DEHP & 10.0 & $y=2.30 x+807$ & 0.9998 & $70.0-10000$ & 70.0 & 233 & 35.0 & 117 & 35.0 & 117 \\
\hline & DnOP & 10.2 & $y=2.45 x-27.9$ & 0.9998 & $64.0-10000$ & 64.0 & 213 & 32.0 & 107 & 32.0 & 107 \\
\hline
\end{tabular}

aOD and LOQ calculated from the analytical curve; ${ }^{b} \mathrm{LOD}$ and LOQ calculated considering a nominal sampled seawater volume of $1.0 \mathrm{~L}$ and the concentration step to $500 \mu \mathrm{L}$ during sample preparation; ${ }^{c} \mathrm{LOD}$ and $\mathrm{LOQ}$ for solid samples considering a nominal average mass $=1 \mathrm{~g}$ dw. $\mathrm{t}_{\mathrm{R}}$ : retention time; LOD: limit of detection; LOQ: limit of quantification; dw: dried weight; E3: estriol; BPA: bisphenol A; E2: 17ß-estradiol; EE2: ethynylestradiol; E1: estrone; 4tOP: 4-t-octylphenol; 4nOP: 4-n-octylphenol; 4nNP: 4-n-nonylphenol; DMP: dimethylphthalate; DEP: diethylphthalate; BBP: butylbenzylphthalate; DBP: di- $n$-butylphthalate; DEHP: di-(2-ethylhexyl)phthalate; DnOP: di- $n$-octylphthalate. 
example, EE2, 4tOP, and 4nOP) presented values that differed slightly from 1 , indicating that proposed methods are virtually free of significative sample matrix effects and, therefore, standard-addition calibration curves are not needed.

Method precision was assessed in terms of retention time and peak area repeatability. Precision was evaluated by injecting standards at three concentration levels (10 replicates each) within the same day (intra-day precision or repeatability) and in 5 successive days (inter-day precision or intermediate precision), expressed as RSD (\%) (Table S6, SI section). RSD values for both inter-day and intra-day precision were below $6.7 \%$ for peak area and below $0.31 \%$ for retention time. As RSD values up to $20 \%$ for instrumental analysis are generally well accepted, the proposed method is precise. Since there are no commercially available standard reference materials (SRM) for endocrine disrupting-chemicals in any sample matrices, we evaluated method accuracy by performing recovery tests. We added a known amount ( 3 concentration levels) of EDC standards to coastal waters, SPM, and sediment samples for the recovery tests. Standard additions were (A) $10 \mu \mathrm{g} \mathrm{L} \mathrm{L}^{-1}$ (alkylphenols, BPA, hormones), $50 \mu \mathrm{g} \mathrm{L}^{-1}$ estrone, and $2 \mathrm{mg} \mathrm{L}^{-1}$ phthalates; (B) $25 \mu \mathrm{g} \mathrm{L}^{-1}$ (alkylphenols, BPA, hormones), $125 \mu \mathrm{g} \mathrm{L} \mathrm{L}^{-1}$ estrone, and $5 \mathrm{mg} \mathrm{L}^{-1}$ phthalates; and (C) $50 \mu \mathrm{g} \mathrm{L}^{-1}$ (alkylphenols, BPA, hormones), $250 \mu \mathrm{g} \mathrm{L}^{-1}$ estrone, and $10 \mathrm{mg} \mathrm{L}^{-1}$ phthalates. After the standard addition, samples were preconcentrated and analyzed as described previously (Figure S2, SI section).

Extracts were gently dried under $\mathrm{N}_{2}$ flux and resuspended to either 500,250 , and $500 \mu \mathrm{L} \mathrm{MeOH}$ for coastal water, SPM, and sediment samples, respectively (Table S7, SI section). Recoveries ranged from 52 (DEP) to $116 \%$ (DBP) for coastal waters, from 54 (DEP) to 108\% (E1) for SPM, and from $62(4 \mathrm{nNP})$ to $117 \%$ ( $4 \mathrm{nOP})$ for sediments, so our methods are considered to be accurate.

The last step of method validation is to apply the new analytical methods to the samples collected at Todos os Santos Bay. Results for SPM and waters are presented in Table 3, whereas results for sediments are presented in Table 4. Each sample was analyzed in triplicates. From the list of the studied EDCs, the only species not detected in any sample was $4 \mathrm{nOP}$. All the other species were detected at least once. Hormones were detected at low concentrations within the analyzed samples. Considering E1, E2, and E3 are natural steroid hormones released by humans via domestic effluents, they may have been degraded, since emission, by microorganisms. . $, 67,35,75^{\text {The BPA, }} 4 \mathrm{nNP}$, DMP, DEHP, and DnOP were the most frequently detected compounds among the evaluated samples. Figure S8 (SI section) shows chromatograms of coastal waters, SPM, and sediment samples collected in the BTS.

The determination methods proposed in this study present good improvements if compared to other studies.

Table 3. Dissolved EDC concentrations in coastal waters $(n=1)$, and average concentration and one standard deviation of replicates SPM samples from BTS $(n=3)$. Gravimetric results for SPM are presented at the last line of the table

\begin{tabular}{|c|c|c|c|c|c|c|c|c|c|c|}
\hline \multirow[b]{2}{*}{ Analyte } & \multicolumn{2}{|r|}{ ALA } & \multicolumn{2}{|r|}{$\mathrm{CAB}$} & \multicolumn{2}{|r|}{ MAT } & \multicolumn{2}{|r|}{ SFC } & \multicolumn{2}{|r|}{ TMA } \\
\hline & $\begin{array}{c}\mathrm{sw} / \\
\left(\mathrm{ng} \mathrm{L}^{-1}\right)\end{array}$ & $\begin{array}{c}\mathrm{SPM} / \\
\left(\mathrm{ng} \mathrm{g}^{-1} \mathrm{dw}\right)\end{array}$ & $\begin{array}{c}\mathrm{sw} / \\
\left(\mathrm{ng} \mathrm{L}^{-1}\right)\end{array}$ & $\begin{array}{c}\mathrm{SPM} / \\
\left(\mathrm{ng} \mathrm{g}^{-1} \mathrm{dw}\right)\end{array}$ & $\begin{array}{c}\mathrm{sw} / \\
\left(\mathrm{ng} \mathrm{L}^{-1}\right)\end{array}$ & $\begin{array}{c}\mathrm{SPM} / \\
\left(\mathrm{ng} \mathrm{g}^{-1} \mathrm{dw}\right)\end{array}$ & $\begin{array}{c}\mathrm{sw} / \\
\left(\mathrm{ng} \mathrm{L}^{-1}\right)\end{array}$ & $\begin{array}{c}\mathrm{SPM} / \\
\left(\mathrm{ng} \mathrm{g}^{-1} \mathrm{dw}\right)\end{array}$ & $\begin{array}{c}\mathrm{sw} / \\
\left(\mathrm{ng} \mathrm{L}^{-1}\right)\end{array}$ & $\begin{array}{c}\mathrm{SPM} / \\
\left(\mathrm{ng} \mathrm{g}^{-1} \mathrm{dw}\right)\end{array}$ \\
\hline E3 & $<\mathrm{LOD}$ & $<$ LOD & $<$ LOD & $<\mathrm{LOD}$ & $<\mathrm{LOD}$ & $27.5 \pm 1.3$ & $<\mathrm{LOD}$ & $<$ LOD & $<$ LOD & $22.0 \pm 1.8$ \\
\hline BPA & 139 & $126 \pm 16$ & 6.60 & $239 \pm 21$ & 8.90 & $185 \pm 11$ & 31.1 & $152 \pm 18$ & 78.5 & $338 \pm 76$ \\
\hline $\mathrm{E} 2$ & $<\mathrm{LOD}$ & $<$ LOD & $<$ LOD & $<$ LOD & 0.95 & $<\mathrm{LOD}$ & $<$ LOD & $<$ LOD & $<$ LOD & $<$ LOD \\
\hline EE2 & $<\mathrm{LOD}$ & $<\mathrm{LOD}$ & $<$ LOD & $<\mathrm{LOD}$ & $<\mathrm{LOD}$ & $<\mathrm{LOD}$ & 3.21 & $<\mathrm{LOD}$ & $<$ LOD & $<\mathrm{LOD}$ \\
\hline E1 & $<\mathrm{LOD}$ & $<$ LOD & $<$ LOD & $<$ LOD & 22.3 & $<$ LOD & $<$ LOD & $<$ LOD & $<$ LOD & $<$ LOD \\
\hline $4 \mathrm{tOP}$ & 66.0 & $<\mathrm{LOD}$ & 2.10 & $<\mathrm{LOD}$ & $<\mathrm{LOD}$ & $<\mathrm{LOD}$ & $<\mathrm{LOD}$ & $<\mathrm{LOD}$ & 2.32 & $<\mathrm{LOD}$ \\
\hline $4 \mathrm{nOP}$ & $<$ LOD & $<$ LOD & $<$ LOD & $<$ LOD & $<\mathrm{LOD}$ & $<$ LOD & $<$ LOD & $<$ LOD & $<$ LOD & $<$ LOD \\
\hline $4 \mathrm{nNP}$ & $<\mathrm{LOD}$ & $367 \pm 18$ & 2.00 & $418 \pm 19$ & 4.16 & $368 \pm 25$ & 3.34 & $402 \pm 19$ & 3.41 & $670 \pm 90$ \\
\hline DMP & $<\mathrm{LOD}$ & $23260 \pm 128$ & 1244 & $9984 \pm 63$ & 851 & $18710 \pm 1230$ & 1795 & $21631 \pm 3067$ & 748 & $30251 \pm 1543$ \\
\hline DEP & $<$ LOD & $2539 \pm 203$ & $<$ LOD & $5045 \pm 46$ & $<$ LOD & $<\mathrm{LOD}$ & $<$ LOD & $3846 \pm 515$ & $<$ LOD & $2496 \pm 515$ \\
\hline $\mathrm{BBP}$ & 420 & $3714 \pm 267$ & $<$ LOD & $25703 \pm 680$ & $<$ LOD & $25908 \pm 3039$ & 63.6 & $13990 \pm 746$ & $<$ LOD & $23555 \pm 3313$ \\
\hline DBP & $<$ LOD & $917570 \pm 9890$ & $<$ LOD & $<$ LOD & $<\mathrm{LOD}$ & $51527 \pm 4073$ & $<$ LOD & $30246 \pm 4531$ & $<$ LOD & $1817 \pm 321$ \\
\hline DEHP & 905 & $55786 \pm 1830$ & $<$ LOD & $24030 \pm 68$ & $<\mathrm{LOD}$ & $33852 \pm 5305$ & $<$ LOD & $11524 \pm 642$ & $<$ LOD & $206986 \pm 37415$ \\
\hline DnOP & $<$ LOD & $49681 \pm 4943$ & 75.6 & $155927 \pm 307$ & 46 & $65115 \pm 7624$ & 85.7 & $17107 \pm 667$ & 54.5 & $628497 \pm 66763$ \\
\hline $\mathrm{SPM} /\left(\mathrm{mg} \mathrm{L}^{-1} \mathrm{dw}\right)$ & & 22 & & 2.0 & & 3.9 & & 6.6 & & 4.0 \\
\hline
\end{tabular}

EDCs: endocrine-disrupting compounds; ALA: Alagados; CAB: Caboto; MAT: Mataripe; SFC: São Francisco do Conde; TMA: Terminal Marítimo; sw: seawater; SPM: suspended particulate matter; E3: estriol; BPA: bisphenol A; E2: 17 $\beta$-estradiol; EE2: ethynylestradiol; E1: estrone; 4tOP: 4-t-octylphenol; 4nOP: 4- $n$-octylphenol; 4nNP: 4- $n$-nonylphenol; DMP: dimethylphthalate; DEP: diethylphthalate; BBP: butylbenzylphthalate; DBP: di- $n$-butylphthalate; DEHP: di-(2-ethylhexyl)phthalate; DnOP: di-n-octylphthalate.; LOD: limit of detection. 
Table 4. Average concentration and one standard deviation of the EDCs in sediment samples $(n=3)$ collected from the Subaé Estuary BTS

\begin{tabular}{|c|c|c|c|c|}
\hline \multirow{2}{*}{ Analyte } & \multicolumn{4}{|c|}{ Concentration / $\left(\mathrm{ng} \mathrm{g}^{-1} \mathrm{dw}\right)$} \\
\hline & 1 & 2 & 3 & 4 \\
\hline$\overline{\mathrm{E} 3}$ & $<$ LOD & $<$ LOD & $<$ LOD & $<$ LOD \\
\hline BPA & $1.89 \pm 1.0$ & $<\mathrm{LOD}$ & $<$ LOD & $1.08 \pm 0.076$ \\
\hline $\mathrm{E} 2$ & $<\mathrm{LOD}$ & $<$ LOD & $<$ LOD & $<$ LOD \\
\hline EE2 & $<\mathrm{LOD}$ & $<$ LOD & $<$ LOD & $<$ LOD \\
\hline E1 & $<\mathrm{LOD}$ & $<\mathrm{LOD}$ & $3.79 \pm 0.26$ & $4.37 \pm 0.31$ \\
\hline $4 \mathrm{tOP}$ & $40.0 \pm 2.7$ & $32.1 \pm 4.2$ & $62.7 \pm 1.7$ & $61.4 \pm 5.1$ \\
\hline $4 \mathrm{nOP}$ & $<\mathrm{LOD}$ & $<$ LOD & $<$ LOD & $<$ LOD \\
\hline $4 \mathrm{nNP}$ & $3.18 \pm 0.18$ & $3.34 \pm 0.12$ & $2.54 \pm 0.18$ & $1.83 \pm 0.13$ \\
\hline DMP & $1285 \pm 65$ & $3318 \pm 186$ & $1721 \pm 31$ & $1686 \pm 90$ \\
\hline DEP & $<\mathrm{LOD}$ & $46.9 \pm 3.3$ & $<$ LOD & $51.5 \pm 4.1$ \\
\hline BBP & $<$ LOD & $68.2 \pm 1.5$ & $339 \pm 10$ & $373 \pm 29$ \\
\hline DBP & $267 \pm 13$ & $341 \pm 11$ & $265 \pm 9.8$ & $313 \pm 27$ \\
\hline DEHP & $380 \pm 18$ & $688 \pm 20$ & $407 \pm 9.7$ & $321 \pm 19$ \\
\hline DnOP & $494 \pm 17$ & $307 \pm 6.5$ & $637 \pm 28$ & $667 \pm 63$ \\
\hline
\end{tabular}

<LOD: below the limit of detection; E3: estriol; BPA: bisphenol A; E2: 17ß-estradiol; EE2: ethynylestradiol; E1: estrone; 4tOP: 4-t-octylphenol; 4nOP: 4- $n$-octylphenol; 4nNP: 4- $n$-nonylphenol; DMP: dimethylphthalate; DEP: diethylphthalate; BBP: butylbenzylphthalate; DBP: di- $n$-butylphthalate; DEHP: di-(2-ethylhexyl)phthalate; DnOP: di- $n$-octylphthalate; dw: dry weight.

First of all, without using mass spectrometry detectors (MS or MS/MS) coupled to liquid chromatographs, we could reach LODs and LOQs either as low as or lower than LODs from other studies in the literature, as stated in Tables S3 and $\mathrm{S} 4$, and references therein. Our LODs/LOQs were low enough to achieve the detection of the 14 analytes at typical environmental levels of coastal environments. Hence our method using UFLC-PDA-FLD is adequate to be employed in environmental monitoring programs.

As for the results presented for the dissolved fraction, there is a sample of the three collected at each point. We chose not to analyze the field replicates because they have low variability. ${ }^{10}$ For the sediment and MPS, three bench replicates were made that demonstrated low variability (RSD $<15 \%$ for MPS and RSD $<10 \%$ for sediment). The set formed by extraction and determination methods guarantees a quick and efficient analysis of the EDCs in three important environmental sample matrices. With this, it is possible to measure the levels of contamination that these products present in coastal environments and gain insight into the processes that control their distribution and fate.

\section{Conclusions}

In order to assess the occurrence and dynamics of EDCs in coastal environments, analytical methodologies were developed for sample preparation (extraction, clean up, and pre-concentration) of water, sediment, and SPM, as well as chromatographic analysis by a UFLC-DAD-FLD system. Those methods approach the Principles of the Green
Analytical Chemistry. In addition, we pursued procedures that use reduced sample size, fast chromatographic analyses, and being reliable and cost-effective. In this way, the proposed methods could be eligible as a substitute to conventional, time-consuming methods (such as Soxhlet and liquid-liquid (LLE) extractions) in routine analysis or standardized protocols in the future.

\section{Supplementary Information}

Supplementary data are available free of charge at http://jbcs.sbq.org.br as PDF file.

\section{Acknowledgments}

This work was supported by the Fundação de Apoio à Pesquisa do Estado da Bahia (FAPESB, Project No. 1663/2011; PET0034/2012; CVN0049/2008) and the Conselho Nacional de Desenvolvimento Científico e Tecnológico (CNPq No. 465497/ 2014-4). This study was also partially financed by the Coordenação de Aperfeiçoamento de Pessoal de Nível Superior-Brasil (CAPES)-Finance Code 001. G. C. thanks FAPESB and C. S. F. thanks CAPES for their PhD scholarships. V. H. and G. O. R. are thankful for CNPq for their research fellowship.

\section{Author Contributions}

GabrielC. de Souza was responsible for conceptualization, data curation, investigation, software, validation, visualization, writing original draft, writing-review and 
editing; Cristiane S. Fahning for conceptualization, investigation, software, validation, visualization; Vanessa Hatje for formal analysis funding acquisition, project administration, resources, visualization, writing original draft, writing-review and editing; Gisele O. da Rocha for conceptualization, data curation, formal analysis funding acquisition, project administration, resources, visualization, writing original draft, writing-review and editing.

\section{References}

1. Staniszewska, M.; Koniecko, I.; Falkowska, L.; Krzymyk, E.; Mar. Pollut. Bull. 2015, 91, 372.

2. Liu, D.; Guo, M.; Xu, H.; Zhang, S.; Shi, L.; Yao, C.; Mar. Pollut. Bull. 2016, 112, 142.

3. Zhang, Q.; Song, J.; Li, X.; Peng, Q.; Yuan, H.; Li, N.; Duan, L.; Ma, J.; Mar. Pollut. Bull. 2019, 140, 107.

4. Williams, M.; Kookana, R. S.; Mehta, A.; Yadav, S. K.; Tailor, B. L.; Maheshwari, B.; Sci. Total Environ. 2019, 647, 1256.

5. Kim, S.; Lee, Y. S.; Moon, H.-B.; Mar. Pollut. Bull. 2020, 151, 110824.

6. Cotrim, G.; Fahning, C. S.; Hatje, V.; da Rocha, G. O.; J. Integr. Coastal Zone Manage. 2016, 16, 299.

7. Encarnação, T.; Pai, A. A. C. C.; Campos, M. G.; Burrows, H. D.; Sci. Prog. 2019, 102, 3.

8. de Araujo, F. G.; Bauerfeldt, G. F.; Cid, Y. P.; An. Acad. Bras. Cienc. 2018, 90, 1903.

9. Acir, I.-H.; Guenther, K.; Sci. Total Environ. 2018, 635, 1530.

10. Lisboa, N. S.; Fahning, C. S.; Cotrim, G.; dos Anjos, J. P.; de Andrade, J. B.; Hatje, V.; da Rocha, G. O.; Talanta 2013, 117, 168.

11. Rodrigues, M. O.; Abrantes, N.; Gonçalves, F. J. M.; Nogueira, H.; Marques, J. C.; Gonçalves, A. M. M.; Environ. Toxicol. Pharmacol. 2019, 72, 103239.

12. Gu, Y.; Yu, J.; Hu, X.; Yin, D.; Sci. Total Environ. 2016, 539, 460.

13. Yang, L.; Cheng, Q.; Lin, L.; Wang, X.; Chen, B.; Luan, T.; Tam, N. F. Y.; Environ. Pollut. 2016, 211, 58.

14. Jeon, S.; Hong, S.; Kwon, B.-O.; Park, J.; Song, S. J.; Giesy, J. P.; Khim, J. S.; Chemosphere 2017, 168, 441.

15. Chen, C.-F.; Chen, C.-W.; Ju, Y.-R.; Dong, C.-D.; Mar. Pollut. Bull. 2017, 124, 767.

16. World Health Organization (WHO); State of the Science of Endocrine Disrupting Chemicals; United Nations Environment Programme, 2012, p. 30, available at https://apps.who.int/iris/ handle/10665/78102, accessed in July 2021.

17. United Nations Environment Programme (UNEP); Global Chemicals Outlook: Towards Sound Management of Chemicals, 2013, available at https://www.unep.org/resources/report/ global-chemicals-outlook-towards-sound-managementchemicals, accessed in July 2021.
18. United Nations Environment Programme (UNEP); Global Chemicals Outlook II: From Legacies to Innovative Solutions, 2019, available at https://www.unep.org/resources/report/ global-chemicals-outlook-ii-legacies-innovative-solutions, accessed in July 2021.

19. Zhao, X.; Grimes, K. L.; Colosi, L. M.; Lung, W. S.; Chemosphere 2019, 230, 462.

20. Sghaier, R. B.; Net, S.; Ghorbel-Abid, I.; Bessadok, S.; Le Coz, M.; Hassan-Chehimi, D. B.; Trabelsi-Ayadi, M.; Tackx, M.; Ouddane, B.; Water, Air, Soil Pollut. 2017, 228, 2.

21. Sghaier, R. B.; Tlili, I.; El Atrache, L. L.; Net, S.; Ghorbel-Abid, I.; Ouddane, B.; Hassan-Chehimi, D. B.; Trabelsi-Ayadi, M.; Int. J. Environ. Res. 2017, 11, 613.

22. Goodman, J. E.; Peterson, M. K. In Encyclopedia of Toxicology, $3^{\text {rd }}$ ed.; Wexler, P., ed.; Elsevier, 2014, p. 514-518.

23. Grand View Research, Bisphenol A Market Size Worth $\$ 20.03$ Billion by 2020, http://grandviewresearch.com/press-release/ global-bisphenol-a-bpa-market, accessed in July 2021.

24. Ceresana's Latest Report Details Growth and Change for Global Plasticizers Market; Addit Polym. 2019, 6, 11.

25. Dai, R.; Edwards, M. R.; Heid, B.; Ahmed, A.; Endocrinology 2019, 160, 101.

26. Salgueiro-González, N.; Muniateghi-Lorenzo, N. S.; LópezMahía, P.; Prada-Rodríguez, D.; Anal. Chim. Acta 2017, 962, 1.

27. Salgueiro-González, N.; Castiglioni, S.; Zuccato, E.; TurnesCarou, I.; López-Mahía, P.; Muniateghi-Lorenzo, S.; Anal. Chim. Acta 2018, 1024, 39.

28. Net, S.; Sempéré, R.; Delmont, A.; Paluselli, A.; Ouddane, B.; Environ. Sci. Technol. 2015, 49, 4019.

29. Fan, W.; He, M.; You, L.; Chen, B.; Hu, B.; J. Sep. Sci. 2020 , 43, 1137.

30. Huysman, S.; van Meulebroaek, L.; Janssens, O.; Vanryckeghem, F.; van Langenhove, H.; Demeestere, K.; Vanhaecke, L.; Anal. Chim. Acta 2019, 1049, 141.

31. Mignot, M.; Nagels, M.; Poelmans, S.; Kensert, A.; Dries, J.; Dewil, R.; Cabooter, D.; Anal. Bioanal. Chem. 2019, 411, 1611.

32. Errico, S.; Chioccarelli, T.; Moggio, M.; Diano, N.; Cobellis, G.; Molecules 2020, 25, 48.

33. Wei, N.; Zheng, Z.; Wang, Y.; Tao, Y.; Shao, Y.; Zhu, S.; You, J.; Zhao, X.-E.; Rapid Commun. Mass Spectrom. 2017, 31, 937.

34. Barreca, S.; Busetto, M.; Colzani, L.; Clerici, L.; Daverio, D.; Dellavedova, P.; Balzamo, S.; Calabretta, E.; Ubaldi, V.; Microchem. J. 2019, 147, 1186.

35. de Araujo, F. G.; Bauerfeldt, G. F.; Cid, Y. P.; J. Braz. Chem. Soc. 2018, 29, 2046.

36. Sung, Y.-H.; Liu, C.-H.; Leong, M.-I.; Huang, S.-D.; Anal. Lett. 2014, 47, 2643.

37. Shih, H.-K.; Shu, T.-Y.; Ponnusamy, V. K.; Ken, J.-F.; Anal. Chim. Acta 2015, 854, 70.

38. Duan, X.-Y.; Li, Y.-X.; Li, X.-G.; Zhang, D.-H.; Gao, Y.; Chemosphere 2014, 107, 265. 
39. Li, B.; Gao, H.; Tan, R.; Zeng, P.; Song, Y.; Environ. Pollut. 2016, 219, 409.

40. Weizhen, Z.; Xiaowei, Z.; Peng, G.; Ning, W.; Zini, L.; Zheng, Z.; Environ. Sci. Pollut. 2020, 27, 12550.

41. Wang, B.; Dong, F.; Chen, S.; Chen, M.; Bai, Y.; Tan, J.; Li, F.; Wang, Q.; Ecotoxicol. Environ. Saf. 2016, 128, 133.

42. Casatta, N.; Mascolo, G.; Roscioli, C.; Vigano, L.; Sci. Total Environ. 2015, 511, 214.

43. Han, X.; Liu, D.; PLoS One 2019, 14, e0213398.

44. Ma, L.; Yates, S. R.; TrAC, Trends Anal. Chem. 2018, 109, 142.

45. van der Berg, C.; Venter, G.; van der Westhuizen, F. H.; Erasmus, E.; Anal. Biochem. 2020, 590, 113531.

46. Omar, T. F. T.; Ahmad, A.; Aris, A. Z.; Yusoff, F. M.; TrAC, Trends Anal. Chem. 2016, 85, 241.

47. Lopardo, L.; Rydevik, A.; Kasprzyk-Hordern, B.; Anal. Bioanal. Chem. 2019, 411, 689.

48. Barros, F.; Hatje, V.; Figueiredo, M. B.; Magalhães, W. F.; Dórea, H. S.; Emídio, E. S.; Estuarine, Coastal Shelf Sci. 2008, $78,753$.

49. Egli, H.; Dassenakis, M.; Garelick, H.; Grieken, R. V.; Peijnenburg, W. J. G. M.; Klasinc, L.; Kördel, W.; Priest, N.; Tavares, T.; Pure Appl. Chem. 2003, 75, 1097.

50. Thompson, M.; Ellison, S. L. R.; Wood, R.; Pure Appl. Chem. 2002, 74, 835 .

51. Vessman, J.; Stefan, R. I.; Staden, J. F. V.; Danzer, K.; Lindner, W.; Burns, D. T.; Fajgelj, A.; Müller, H.; Pure Appl. Chem. 2001, 73,1381 .

52. Thompson, M.; Ellison, S. L. R.; Fajgelj, A.; Willetts, P.; Wood, R.; Pure Appl. Chem. 1999, 71, 337.

53. Domingos, J. S. S.; Regis, A. C. D.; Santos, J. V. S.; de Andrade, J. B.; da Rocha, G. O.; J. Chromatogr. A 2012, 1266, 17.

54. Santos, A. G.; Regis, A. C. D.; da Rocha, G. O.; Bezerra, M. A.; de Jesus, R. M.; de Andrade, J. B.; J. Chromatogr. A 2016, 1435,6 .

55. Nascimento, M. M.; da Rocha, G. O.; de Andrade, J. B.; Sci. Rep. 2017, 7, 2267.

56. Nascimento, M. M.; da Rocha, G. O.; de Andrade, J. B.; Microchem. J. 2018, 139, 424.
57. Nascimento, M. M.; da Rocha, G. O.; de Andrade, J. B.; Talanta 2019, 204, 776.

58. Sodré, F. F.; Antonio, M.; Locatelli, F.; Jardim, W. F.; Quim. Nova 2010, 33, 216.

59. Sánchez-Avila, J.; Fernandez-Sanjuan, M.; Vicente, J.; Lacorte, S.; J. Chromatogr. A 2011, 1218, 6799.

60. Arditsoglou, A.; Voutsa, D.; Environ. Sci. Pollut. Res. 2008, 15, 228.

61. Yu, Y.; Huang, Q.; Cui, J.; Zhang, K.; Tang, C.; Peng, X.; Anal. Bioanal. Chem. 2011, 399, 891.

62. Zhang, S.; You, J.; Sun, Z.; Song, C.; Ning, S.; Zhao, C.; Suo, Y.; Microchem. J. 2012, 103, 90.

63. Kozlík, P.; Bosáková, Z.; Tesařová, E.; Coufal, P.; Cabala, R.; J. Chromatogr. A 2011, 1218, 2127.

64. Samaras, V. G.; Thomaidis, N. S.; Stasinakis, A. S.; Lekkas, T. D.; Anal. Bioanal. Chem. 2011, 399, 2549.

65. Cailleaud, K.; Forget-Leray, J.; Souissi, S.; Lardy, S.; Augagneur, S.; Budzinski, H.; Chemosphere 2007, 70, 281.

66. Shen, H.-Y.; Talanta 2005, 66, 734.

67. Heemken, O. P.; Theobald, N.; Wenclawiak, B. W.; Anal. Chem. 1997, 69, 2171.

68. Queiroz, F. B.; Silva, J. C.; Aquino, S. F.; Coutrim, M. X.; Afonso, R. J. C. F.; J. Braz. Chem. Soc. 2014, 25, 298.

69. Smith, E.; Coffey, M.; J. Environ. Monit. 2001, 3, 616.

70. Li, J.; Cai, Y.; Shi, Y.; Mou, S.; Jiang, G.; Talanta 2008, 74, 498.

71. Ferguson, P. L.; Iden, C. R.; McElroy, A. E.; Brownawell, B. J.; Anal. Chem. 2001, 73, 3890.

72. Santos, A. G.; da Rocha, G. O.; de Andrade, J. B.; Sci. Rep. 2019, 9, 1.

73. Ribani, M.; Collins, C. H.; Bottoli, C. B. G.; J. Chromatogr. A 2007, 1156, 201.

74. Ribani, M.; Bottoli, C. B. G.; Collins, C. H.; Jardim, I. C. S. F.; Melo, L. F. C.; Quim. Nova 2004, 27, 771.

75. Chokwe, T. B.; Okonkwo, J. O.; Sibali, L. L.; Water SA 2017, 43,529 .

Submitted: March 17, 2021 Published online: July 28, 2021 